\title{
DEVELOPMENT AND PRESENTATION OF AN ETHICAL FRAMEWORK FOR HEALTH AND MEDICAL APPS
}

\author{
Pinar Tokgöz BSc, Hannah Eger BSc, Sarah Sharlyn Funke BSc, Alexander Gutjar BSc, Thuy Nguyen-Thi \\ BSc, Christoph Dockweiler PhD
}

School of Public Health, Bielefeld University, Germany

\begin{abstract}
The ubiquity of mobile applications makes it difficult to weigh up opportunities and potential risks. One significant aspect of an ethical assessment regarding the development and use of health and medical apps is the lack of clear and consistent guidelines and measures of value. Aim: The aim of this paper was to identify the main ethical determinants associated in the context of health and medical apps and develop a framework for ethical reflection. Methods: A systematic literature search in the database PubMed was undertaken and the journal Biomed Central Medical Ethics was hand searched and 32 met the review criteria. On this basis of the review an interview guide was developed and five purposively selected experts on the field of payers, science, consumers, medical ethics and society were interviewed regarding health and medical apps. Resul ts: There is a lack of consistent and clear guidelines regarding the use of health and medical apps in literature. Indeed, findings refer to established biomedical principles. The interviews identified that several insecurities related to legal and regulatory issues are common. On the other hand, many advantages of the use of health and medical apps have been pointed out by experts. Conclusion: Debates on ethics and the use of health and medical apps should play a significant role in public discussion. Ethical endpoints cannot be considered isolated from each other, and must be regarded as a complex network of aspects connected with each other. Further research should concentrate on the development of consistent guidelines and a framework for reflection of occurring ethical concerns.
\end{abstract}

Keywords: mHealth; apps; healthcare; medical ethics

Tokgoz P, et al. JISfTeH 2019;7:e15(1-8).

DOI: https://doi.org/10.29086/JISfTeH.7.e15

Copyright:@ The Authors 2018

Open access, published under Creative Commons Attribution 4.0 BY International Licence

\section{Introduction}

Digitalisation is currently having an increasing impact on the health sector. ${ }^{1}$ In healthcare, the term "digitalisation" refers to eHealth and mHealth applications. ${ }^{2}$ The use of modern information and communication technologies in the context of health and disease is summarised under the term eHealth. ${ }^{3}$ As a part of this, health and medical apps become more important. Due to the high usage rates of new media and the associated simple accessibility for users, the range and possibilities of using health and medical apps is steadily growing. ${ }^{4}$

Health and medical apps describe applications on mobile devices (e.g. smartphones or tablets) that deal with topics of medicine and health in various ways. ${ }^{5}$ The possible spectrum of applications is diverse and ranges from health apps, for example on health issues for interested citizens, to medical apps for persons and their relatives dealing with illness in a specific care context. Medical apps could be helpful for selfmanagement through knowledge transfer or for promoting the motivational components, as well as being used as an application in therapy and diagnostics (e.g. monitoring of disease-relevant vital parameters). A strict differentiation of usage context is not entirely possible, since e.g. applications used to monitor certain parameters can also be used in the field of treatment or research. ${ }^{6}$

The complexity in healthcare and the lack of a solid information base make it difficult for users to weigh up opportunities and risks of using such apps. ${ }^{6}$ In the light of potential risks, questions referring to ethical conflicts are raised repeatedly. The state of research in Germany regarding barriers and challenges as well as the ethical implications of the use of health and medical apps is fragmented. ${ }^{4}$ There is a lack of clear and consistent guidelines on how to ethically develop and use health and medical apps to avoid negative consequences and to maximise their potential for healthcare.

Within this work, initially, the ethical aspects linked to the use of health and medical apps in literature will be presented systematically. Concerning this, there is no restriction regarding application context, specific indication or population group. Based on this, perspectives from different stakeholders (e.g. citizens, patients, service 
providers, payers) are integrated in form of expert discussions through a participatory approach. The aim of this study is to develop a framework that shows the current state of discussion and expand it empirically, to provide a base for ethical reflection in the field of health and medical apps.

\section{Methods}

\section{Literature review}

To determine the ethical aspects associated with health and medical apps, a two-part procedure was chosen. As a first step, a systematic literature search was conducted between November and December 2017. Considering the fast-moving field of health and medical apps as well as the publication activity in this field a revision of the search has been conducted in January 2019. (Figure 1) For this, the following search terms were selected: (apps OR phone apps OR mobile apps) AND (healthcare OR health system) AND (ethics OR morals OR ethical implications). References from the last ten years (2008-2018) were included. Further publications were identified through search by hand in the database of BioMed Central Medical Ethics using the same search terms. Additionally, the reference lists of included publications were screened. Only German and English publications without restrictions in study design or type of publication (e.g. articles in scientific journals, reports from ministries), but referring to ethical implications were considered as inclusion criteria. Due to divergent systematic and cultural structures, implications in non-European or non-AngloAmerican countries were excluded. Not referring to ethical implications has been set as an exclusion criterion as well. Interview Guide

From the 32 relevant studies fundamental ethical implications of the use of health and medical apps were extracted and transferred to a theoretical model. Based on that, an interview guide was created in the second step. The questionnaire consisted of four main categories (respect for autonomy, non-maleficence, beneficence, justice). ${ }^{7}$ These were extended by general questions about present developments as well as future implications and strategies of action. To be able to map the complex networks and interdependencies, an interdisciplinary approach was pursued.

Selection of the Sample and Interviewing process

Five different stakeholders in the fields of medical ethics, consumers, society, science and payers were purposively selected and interviewed about ethical aspects and the use of health and medical apps. The selection of the sample is aligned to their importance for the healthcare sector. The interviewees were, on the one hand, people who deal and are familiar with health and medical apps and on the other hand represent their subpopulation adequately. Medical ethics represent the moral values that are important when dealing with digitalisation in healthcare and to clarify the consequences and potentials on an individual and societal dimension. Furthermore, it is essential to acknowledge how consumers position themselves in this development. For this purpose, the representative of consumers has been consulted to get their point of view in the broadest sense. However, the other perspective to be considered is the representative of society at organisational level. In this, non-profit and commercial interests are combined, so that a different point of view is presented. A debate on digital development in healthcare requires also a scientific approach. The representative of research focuses on different fields of applied science and is important regarding society's research priorities. Another essential group is the representative of payers in healthcare. This group implicates entities that finance the cost of health services and thus play an important role in the reimbursement of innovations, like health and medical apps.

The interviews took place from December 2017 to January 2018 with an average length of 40 minutes per interview. All interviews except one face-to-face interview were phone based. The interviews were recorded and transcribed following the structuring content analysis according to Mayring. ${ }^{8}$ Due to the sample size as well as the purposive selection of experts, the degree of results should be considered as not globally representative. Finally, the interview results were evaluated and summarised with the information obtained from the literature search. The interview results are presented as indirect citations to prevent mistranslation and for a better understanding of key messages.

\section{Results}

Within the first step, 245 references were identified in PubMed and the BioMed Central (04.01.2019). Based on that, 16 publications met the predetermined inclusion criteria and another 16 publications were included through search by hand. A total of 32 references has been included in this review. (Figure 1) Of these, 18 references were journal articles,,${ }^{9-26}$ seven reviews, ${ }^{27-33}$ three systematic reviews, ${ }^{34-36}$ two survey results from Australia ${ }^{37}$ and the USA, ${ }^{38}$ one study report from Germany ${ }^{6}$ and one qualitative study from Australia. ${ }^{39}$

For further discourse, the principles of biomedical ethics defined by Beauchamp and Childress function as ethical endpoints. ${ }^{7}$ Additional ethical aspects discussed in literature, such as privacy, regulation, transparency, access, control, social inequalities and discrimination, have been subsumed under these main categories. (Table 1) All references emphasise the use of health and medical apps from an additional ethical perspective, but with differences in application context.

Most publications relate to ethical implications in monitoring and clinical care from the perspective of users and patients. Numerous publications discuss the general risks and the involved ethical challenges. $6,9,13,15,17,21-23,26,29,30$ 


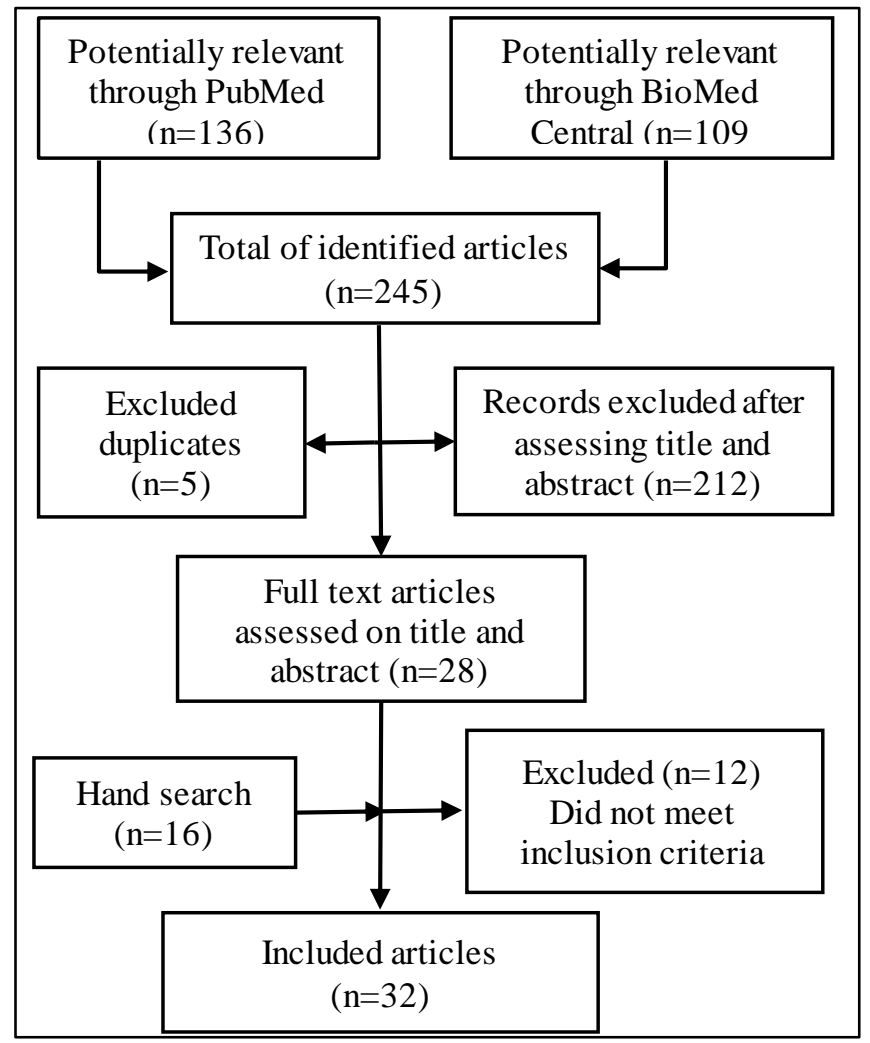

Figure 1. Flowchart for the identification of relevant literature.

Mobile applications become even more apparent being used to prevent and treat diseases, such as chronic alcohol abuse, HIV or the use in routine psychiatric care. ${ }^{10,19,24,25,27,28}$ Furthermore, publications address the use of health and medical apps designed for specific indications, for example in the field of dermatology, pain management or Parkinson's disease..$^{12,35,37}$
One reference examined the use of mobile applications against the background of different social circumstances and settings and two publications address the ethical challenges linked with health and medical apps in aging societies. $18,36,38$ Only one reference deals with the perspective of service providers. ${ }^{25}$ In addition, several publications have highlighted the use of health applications in research and related ethical challenges. ${ }^{16,31,32,38}$ Five publications deal with ethical concerns regarding the regulation and approval of health and medical apps. ${ }^{6,11,18,33,34}$ Only one publication addresses developers of health and medical apps and emphasises ethical principles that should be considered in the development phase. ${ }^{33}$

Concept of respect for autonomy

The term "autonomy" is defined as an inner attitude, moreover as a form of self-determination. ${ }^{40}$ It is a multifactorial concept consisting of various elements. It also covers the handling of personal and sensitive information whereby transparency and privacy play an essential role..$^{41}$ In healthcare, this term implies criteria such as the right of selfdetermination, access to information, informed consent and voluntariness. ${ }^{42}$ Sixteen publications primarily consider these concepts. $6,9,10,12,13,15,16,20,21,22,25,26,30,31,37,38$

In this context, privacy means having the individual right to be in control of the collection, use and transfer of personal data whereby the ways of delivering information should be communicated transparently. ${ }^{10,12,13,16,20,31,32}$ The confidential handling of sensitive information can be ensured, for example by encryption via password or access authorisation by authorised persons. ${ }^{10,14,23}$ Privacy includes data privacy, personal privacy and security. ${ }^{22}$ Security refers to both the protection of personal information and technological security. Therefore, harm caused by the medical device itself or through information delivered by the application should be prevented. ${ }^{18,36}$

Table 1. Classification due to ethical implications.

\begin{tabular}{|c|c|}
\hline Ethical Principle & References \\
\hline $\begin{array}{l}\text { Respect for Autonomy } \\
\text { education, information, } \\
\text { voluntariness } \\
\text { freedom of choice } \\
\text { control, self-determination } \\
\text { privacy, confidentiality } \\
\text { transparency }\end{array}$ & $\begin{array}{l}\text { Albrecht et al. }(2015,2016)^{6,9} \text {, Arora et al. }(2014)^{10} \text {, Carter et al. }(2015)^{12} \text {, Chaet et al. }(2017)^{13} \text {, } \\
\text { Gilmartin et al. }(2018)^{15} \text {, Groß et al }(2018)^{30} \text {, Harari et al. }(2016)^{16} \text {, Kunde et al. }\left(2013^{37} \text { Lhotska et }\right. \\
\text { al. }(2016)^{20} \text {, Lucivero et al. }(2017)^{21} \text {, Mittelstadt et al. }(2014)^{22} \text {, Moore et al. }(2017)^{31} \text {, Nebeker et al. } \\
(2017)^{38} \text {, Torous et Roberts }(2017)^{25} \text { Vayena et al. }(2015)^{26}\end{array}$ \\
\hline $\begin{array}{l}\text { Beneficence } \\
\text { regulation } \\
\text { welfare } \\
\text { cost-benefit-analysis }\end{array}$ & $\begin{array}{l}\text { Albrecht et al. }(2015,2016)^{6,9} \text {, Carter et al. }(2015)^{12} \text {, Chaet et al. (2017) }{ }^{13} \text {, Kacetl \& Maresova } \\
(2016)^{18} \text {, La Vega }\left(2014^{34} \text { Labrique et al. }(2013)^{19} \text {, Lhotska et al. }(2016)^{20} \text {, Mittelstadt etal. }(2014)^{22} \text {, }\right. \\
\text { Nebeker et al. }(2017)^{38} \text {, Olff }(2015)^{24} \text {, Sharp \& O'Sullivan }(2017)^{33} \text {, Torous \& Roberts }(2017)^{25}\end{array}$ \\
\hline $\begin{array}{l}\text { Non-maleficence } \\
\text { responsibility } \\
\text { (data) security vs. abuse }\end{array}$ & All except for Clear et al. (2014) ${ }^{29}$ \\
\hline $\begin{array}{l}\text { Justice } \\
\text { dehumanisation, substitution } \\
\text { access } \\
\text { social inequalities, isolation, } \\
\text { discrimination }\end{array}$ & $\begin{array}{l}\text { Albrecht et al. }(2015,2016)^{6,9} \text {, Carter et al. (2015), Chaet et al. }(2017)^{13} \text {, Chan et al. }(2017)^{28} \text {, Clar } \\
\text { et al. }(2014)^{29} \text {, Ho et al. }(2018)^{17} \text {, La Vega }(2014)^{34} \text {, Matthew-Maich et al. }(2016)+36 \text {, Mittelstadt et } \\
\text { al. }(2014)^{22} \text {, Moore et al. }(2017)^{31} \text {, Nebeker et al. }(2017)^{38} \text {, O'Doherty et al. }(2016)^{32} \text {, Olff }(2015)^{24} \text {, } \\
\text { Vayena et al. }(2015)^{26} \text {, Bauer et al. }(2017)^{27}\end{array}$ \\
\hline
\end{tabular}


All those interviewed agreed that health and medical apps enlarge the autonomy of users and, hence, their health literacy and empowerment. According to the consumer representative, by using health and medical apps the users consciously manage their health and are enabled to make their own health-related decisions.

In clinical care, more emphasis is put on so-called "shared decision-making". This model implies that physicians and patients are equal when it comes to deciding, with no part being superior to the other. To enable this concept, the exchange of information and the acknowledgment of the patient by the physician is essential. ${ }^{43}$ In this context, health and medical apps are used more frequently to recreate the doctor-patient-relationship by introducing a right to be consulted concerning health-related decisions for the patients. ${ }^{22}$ This effect, an increased participation of the users in decisions on their own health, was also observed by the representative of the payers. Hence, the users experience a new way of controlling their physical and mental state. ${ }^{39}$ The medical ethicist as well stated a more independent control of one's own health, an improved knowledge and less need of professional help. Hence it appears that health and medical apps recreate the communication structures and relationship between physicians and patients. ${ }^{21,30}$

However, new (technological) dependencies emerge from the ubiquity of new media, which may lead to a reduced autonomy. ${ }^{22}$ Therefore, it is necessary to consider to what extent health and medical apps support the users' selfdetermination and their lifestyle and at which point the border between autonomy and dependency merges. This problem was also seen by the medical ethicist and the representative of society, who emphasised the danger for the users of being too dependent on the technologies. Resulting from this dependency, the self-determination is reduced. The representative of the consumers stated that increasing selfdetermination is not always desired, either by the doctors or by the patients and this requires consideration. Currently, many users are not able to correctly evaluate the data received from health and medical apps (representative of payers). Additionally, one main issue remains, data sovereignty, which is not controllable by the users and thus restricts their autonomy (representative of research; representative of society).

Concept of beneficence

The concept of beneficence includes the behaviour of active participants with the purpose of promoting the well-being of people and promoting additional benefits. Especially regulation of market access, consideration of chances and risks, and integration of individual preferences, needs and interests are predominant here. This aspect is relevant in 13 references. $6,9,12,13,18,19,20,22,24,25,33,35,38$

According consumer, society and payer representatives, health and medical apps have the potential to not only improve intersectoral cooperation by collecting and delivering information but also simplify the self- management of diseases, thus empowering the users and improving their quality of life.

But for these potentials to be enabled, quality assurance is essential. The users ought to be able to recognise and assess the quality of health and medical apps based on certain criteria (representative of the consumers). From the perspective of the interviewed representative of society, market transparency is also important for improving the quality of health and medical apps. This means that by the time the app is being downloaded it must be distinguishable whether it has a certification, which in turn requires certain quality criteria.

From the perspectives of the representatives of society and consumers, health and medical apps should be certified and recommended by medical associations and health insurance companies, so that patients can benefit by having them included in the standard care system. Furthermore, financing health and medical apps that evidentially benefit the user's health could be conceivable via statutory health insurance (representative of the consumers). This would also lead to wider accessibility and efficacy in resource allocation. ${ }^{30}$

Concept of non-maleficence

This aspect describes the prevention of harmful interventions and actions to provide an acceptable relationship between therapeutic benefits and potential risks. ${ }^{9}$ Another important criterion discussed in the context of health and medical apps is the question of responsibilities when technical errors occur. These points, apart from one reference, ${ }^{29}$ can be found in all identified publications.

One way to prevent harm is to focus on the quality and certification of available applications. ${ }^{33}$ However, there are deficiencies. Irrelevant behavioural or personal data can be automatically collected by the medical device, while users are unaware of the further transport of their "secured" data (representative of medical ethics). It occurs essential to upgrade and constantly evaluate security certifications as well as the requirements for recertifications and data ownership policy. ${ }^{27}$

Besides, there are uncertainties regarding a distinction between specific medical devices and those applications that do not meet the necessary requirements. ${ }^{6}$ A balance between personal interests and market-based interests are strongly demanded. In this context, the focus should be on the establishment of a centralized regulation by political interventions. ${ }^{33,34}$ This is important to not only create user safety but also to promote the continuing development of digital innovations. ${ }^{11}$ Nevertheless, constant development can also facilitate disparities in the adaption and use of health and medical apps. ${ }^{27}$

Concept of justice

The term "justice" is mainly defined as a fair distribution of resources which also includes fair treatment of individuals and participation in social life. In addition, it comprises the fair configured access to and the use of health services 
through health and medical apps. Thirteen publications deal with this concept. 6,9,12,13,22,24,26,29,31,32,35,36,38

Access to health services is facilitated by the ubiquity of health and medical apps. The main purpose is to reduce global health inequalities by including groups that are hard to reach, and to enable disease control. ${ }^{12,26,31,35}$ On the one hand this requires technologies which will be configured to be user-friendly, and on the other hand the user needs to possess the required competencies to take advantage of these services. ${ }^{12,24}$ Paradoxically, differences in media competencies and use of health and medical apps lead to exclusion of a certain group of people. ${ }^{29,32,36}$ The scientific representative emphasised the importance of equal treatment for patients who are not using health and medical apps as compared to patients who are using them. From the perspective of the medical ethicist, lack of equality can weaken the principle of solidarity in society. Compared to older adults, younger people are more likely to have the skill to use health and medical apps. This results in discrimination and stigma within society. ${ }^{6,17}$ Regarding demographic development, older people should be more involved in the digital progress. ${ }^{24}$

Furthermore, certified applications should be provided free of charge to users to ensure fair usage (representative of payers). Health and medical apps deemed to be medically useful and effective need to be incorporated into the treatment path. Socioeconomic disparities in society must be addressed to ensure the equitable benefits of health and mobile apps in disease management and therapy. ${ }^{15,17,28}$

\section{Discussion}

The theoretical findings are supported by the results from the qualitative interviews. In research as well as in clinical treatment respect of autonomy and self-determination ought to be the cornerstone of any action. The implementation of health and medical apps in healthcare is justified if patients are thoroughly informed about chances and potential risks and hence being able to give informed consent. ${ }^{9,16,31,38}$ This consequently requires a transparent communication regarding the use of generated information. ${ }^{14,25,32}$ From today's perspective, there is still need for action, considering the chances and risks of health and medical apps regarding the individual's autonomy.

All the interviewees claimed that health and medical apps can only support the users' autonomy if they reach all people equally, especially those in need. Regardless of the socioeconomic or educational status, it must be ensured that the information is available and understandable. Unlike the benefits of medical interventions, there is insufficient scientific evidence concerning the benefits of most application-based measures. As a result, both providers and users have uncertainties regarding their use. ${ }^{35}$ This makes it even more important to build up a basis of trust and promote the user's well-being. ${ }^{13}$ Developers of health and medical apps must become aware of this responsibility and deal with questions about the purpose and usefulness of new applications in early development phase. ${ }^{33}$

In 2015, a review conducted in the United Kingdom found that about two thirds of all considered applications did not have a transparent policy on data security and privacy, and that every sixth application delivered personal information to third parties. ${ }^{34}$ In order to remedy such unsatisfactory tendencies and data insecurity as well as to ensure secure data collection and storage, the European Union (EU) General Data Protection Regulation (GDPR) become effective in all member states on May $25^{\text {th }} 2018$, with the repeal of the Protection Directive 95/46/EC. ${ }^{44}$ The objective is to standardise the varying levels of data protection and privacy in all member states and establish regulations binding for all member states. Essentially, the tightened rules on data protection give users better control over their personal data and enable companies to benefit from fair conditions of competition. Moreover, companies should only be able to collect and process personal data for a clearly defined and legitimate purpose that should be clarified at the time of collection. Also, the duration of storage is strictly limited. Conclusively, this regulation is a first and important step to improve users' control over their data and to provide guidance and decision-making through binding rules. ${ }^{44}$

Along with the concept of non-maleficence, the question arises whether the application "says" what it should "say" or leads to false or incorrect actions and results. ${ }^{33}$ On one hand, health and medical apps can act as a mediator between individuals and health professionals, on the other hand a lack of context information can lead to misdiagnosis or misinterpretation which could be more harmful than beneficial. ${ }^{22}$ In this context, the unresolved question of who is responsible for doing harm is repeatedly taken up. ${ }^{18}$

Furthermore, users are concerned about the progressive digitalisation and the possible loss of the social component and that health and medicals apps will substitute personal interaction with professionals..$^{22,36}$ This leads to loss in human and social values and increasing isolation and lack of participation in social development. ${ }^{6}$ Moreover, the missing of fundamental social contextual information can significantly affect the quality of care. ${ }^{22}$

Discussions on ethical implications of health and medical apps still occur at micro level and are still evolving in Germany. ${ }^{6}$ A population-based perspective is a central concern for public health interventions. For this reason, an ethical framework for the reflection of tensions in the use of health and medical apps should reach beyond an individual perspective. Furthermore, it is necessary to consider different assessment dimensions as well as target contexts to evaluate the effectiveness of public health interventions. Since ethical implications as well as public health issues are not always universal and require an individualised and contextual approach it is difficult to deduce a pattern of generalities. Another difficulty is to establish standardised evaluation 
criteria, as the use of health and medical apps should be assessed in scope of application context. The rational and generalisability of ethical implications often depends on the researchers and decision-makers perspective. The transfer of theoretical findings can take place on different levels in a target context, e.g. the macro, organisational or individual level. ${ }^{45}$

From the results of the review and the interviews, a framework for an ethical reflection concerning the use of health and medical apps has been developed. (Figure 2) This

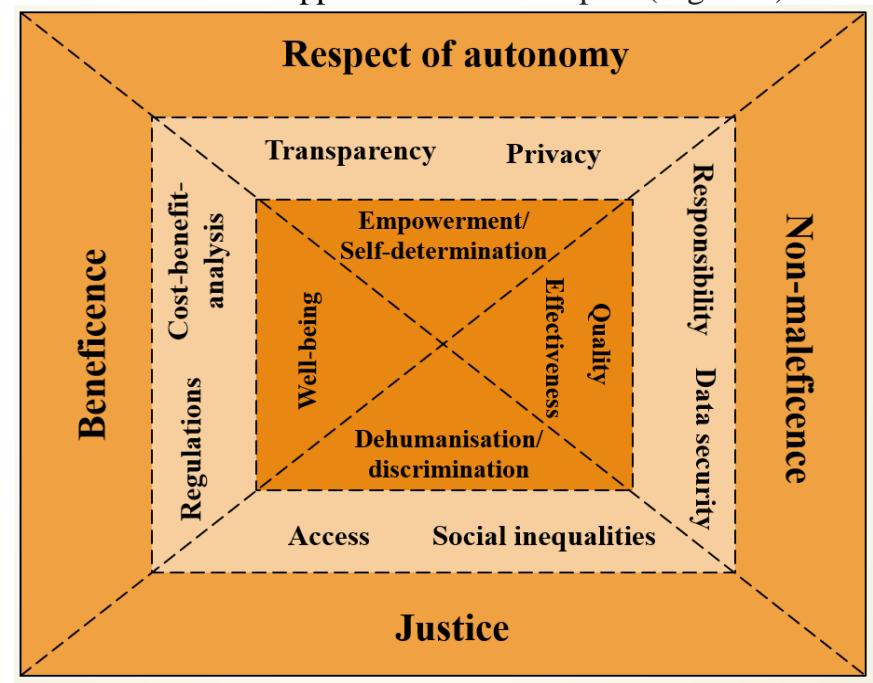

Figure 2. Ethical framework on health and medical apps.

framework includes the four leading aspects of biomedical ethics, as those function as the basis for further identified aspects. The ethical implications presented in this work should not be considered isolated from each other, exemplified by dashed lines in the framework. Single aspects are mutually dependent or do at least facilitate each other, while it is challenging to map out causalities. ${ }^{22}$ It is also unclear which ethical aspects are dominant and pioneering. Furthermore, the multidimensionality of this issue has been underlined with colour gradation. The analysis of ethical implications on different levels ensures a differentiated and detailed assessment. The framework is genuine and consists of normative aspects adaptable to different contexts and public health issues as it increases awareness and sensitivity in responsible actions of healthcare actors alike.

\section{Conclusion}

The aim of this review was to map out ethical implications linked to the use of health and medical apps and to develop a framework for a genuine analysis of arising challenges. This paper only provides a limited approach to ethical implications and does not offer concrete and specific solutions for the problems.

First, health and medical apps seem promising when it comes to increase self-management, empowerment and quality of life. ${ }^{15,17,25}$ These opportunities throw up complex challenges. It should be noted that the use of health and medical apps is not free from risks. Those include problems in the validity of data and security as well as fair data flow, but also the understanding and interpretation of information. ${ }^{17,21}$ Another point is "digital exclusion" of vulnerable groups affected by socio-economic disparities in society and differences in technological literacy. ${ }^{28}$

To affirm the benefits of health and medical apps it is necessary that those attributes are in line with user's expectations and needs. For this it appears important to integrate user and health providers in the conceptualisation and development of health and medical apps alike. To promote data security, transparency and privacy by regulatory authorities appear crucial, as well. Furthermore, the duty to inform potential benefits and risks of the use should be extended and be accompanied by evidence based and objective criteria. Issues of social justice and the prevention of discrimination and stigmatisation of vulnerable groups should receive more attention. Strengthening media and technology literacy is a major point to overcome disparities in access and use of health and medical apps. Finally, health-related policy makers should be integrated more in this field to create a statutory framework and binding specifications to prevent and reduce potential risks for populations.

Taking all these aspects into consideration, it can be said that due to rapid technological developments, ethical approaches at various levels are indispensable, especially as the direction of development is currently difficult to assess.

\section{Corresponding author:}

Pinar Tokgöz

School of Public Health

Bielefeld University

Universitätsstraße 25

D-33615 Bielefeld

Germany

E-Mail: pinar.tokgoez@uni-bielefeld.de

Conflict of interest. The authors declare no conflicts of interest.

\section{References}

1. Neumann K, Larisch K, Dietzel J, et al. Digitale Versorgungsprodukte: Chancen nutzen, sichere Wege in den Markt schaffen. Berlin, IGES, 2016.

2. Gigerenzer G, Schlegel-Matthies K, Wagner GG. Digitale Welt und Gesundheit. eHealth und mHealthChancen und Risiken der Digitalisierung im Gesundheitsbereich. Berlin, SVR, 2016. 
3. Fischer F, Krämer A. eHealth in Deutschland. Berlin,Heidelberg,Springer Berlin Heidelberg, 2016.

4. Rossmann C, Krömer N. mHealth in der medizinischen Versorgung, Prävention und Gesundheitsförderung. In: Fischer F, Krämer A, editors. eHealth in Deutschland. Berlin, Heidelberg: Springer Berlin Heidelberg; 2016;441-456.

5. World Health Organization. mHealth. New horizons for health through mobile technologies. Geneva, WHO, 2011.

6. Albrecht UV. Chancen und Risiken von GesundheitsApps (CHARISMHA). Hannover, Medizinische Hochschule Hannover, 2016.

7. Beauchamp TL, Childress JF. Principles of biomedical ethics ( $7^{\text {th }}$ edition). New York, Oxford University Press, 2013.

8. Mayring P. Qualitative Inhaltsanalyse. Grundlagen und Techniken. Beltz, Weinheim, 2010.

9. Albrecht UV, Reichertz PL. Health apps - sound and trustworthy? World Med J 2015;61(2):75-77. https://www.wma.net/wpcontent/uploads/2016/11/wmj201502.pdf.

10. Arora S, Yttri J, Nilsen W. Privacy and security in mobile health (mhealth) research. Alcohol Res 2014;36(1):143-150. PMID: 26259009.

11. Barton AJ. The regulation of mobile health applications. BMC Med 2012;10(46):1-4. DOI:10.1186/1741-7015-10-46.

12. Carter A, Liddle J, Hall W, Chenery H. Mobile phones in research and treatment. ethical guidelines and future directions. JMIR Mhealth Uhealth 2015;3(4),e95. DOI: $10.2196 /$ mhealth.4538.

13. Chaet D, Clearfield R, Sabin JE, Skimming K. Ethical practice in telehealth and telemedicine. J Gen Intern Med 2017;32(10):1136-1140. DOI: 10.1007/s11606017-4082-2.

14. Eagleson R, Altamirano-Diaz L, McInnis A, et al. Implementation of clinical research trials using webbased and mobile devices. Challenges and solutions. BMC Med Res Methodol 2017;17(1):43. DOI:10.1186/s12874-017-0324-6.

15. Gilmartin C, Arbe-Barnes EH, Diamond M. Varsity medical ethics debate 2018: constant health monitoring - the advance of technology into healthcare. Philos Ethics Humanit Med 2018;13(12):17. DOI: $10.1186 / \mathrm{s} 13010-018-0065-0$.

16. Harari GM, Lane ND, Wang R, et al. Using smartphones to collect behavioral data in psychological science. Opportunities, practical considerations, and challenges. Perspect Psychol Sci 2016;11(6):838-854. DOI: $10.1177 / 1745691616650285$.

17. Ho A, Quick O. Leaving patients to their own devices? Smart technology, safety and therapeutic relationships.
BMC Medical Ethics 2018;19(18):1-6. DOI:10.1186/s12910-018-0255-8.

18. Kacetl J, Maresova P. Legislative and ethical aspects of introducing new technologies in medical care for senior citizens in developed countries. Clin Interv Aging 2016;11:977-984. DOI:10.2147/CIA.S104433.

19. Labrique AB, Kirk GD, Westergaard RP, Merritt MW. Ethical issues in mHealth research involving persons living with HIV/AIDS and substance abuse. AIDS Res Treat 2013;189645:1-6. DOI:10.1155/2013/189645.

20. Lhotska L, Cheshire P, Pharow P, Macku D. Nontechnical issues in design and development of personal portable devices. In: Hofdijk J, et al. editors.

Transforming healthcare with the internet of things. Proceedings of the EFMI Special Topic Conference 2016, Paris. Amsterdam, IOS Press, 2016. 46-50. http://cmapspublic2.ihmc.us/rid=1Q75R3F5CTX84TD-XM/2016\%20\%20Transforming\%20healthcare\%20with\%20the \%20i nternet $\% 20$ of $\% 20$ thing.pdf $\#$ page $=58$

21. Lucivero F, Jongsma KR. A mobile revolution for healthcare? Setting the agenda for bioethics. J Med Ethics 2018;44(10):685-689. DOI:

10.1136/medethics-2017-10474.

22. Mittelstadt B, Fairweather B, Shaw M, McBride N. The ethical implications of personal health monitoring. Int J Technoethics 2014;5(2):37-60. DOI: 10.4018/ijt.2014070104.

23. Myers J, Frieden TR, Bherwani KM, Henning KJ. Ethics in public health research: Privacy and public health at risk: Public health confidentiality in the digital age. Am J Public Health 2008;98(5):793801.DOI: 10.2105/AJPH.2006.107706.

24. Olff M. Mobile mental health: a challenging research agenda. Eur J Psychotraumatol 2015; 6:27882. DOI: 10.3402/ejpt.v6.27882.

25. Torous J, Roberts LW. The ethical use of mobile health technology in clinical psychiatry. J Nerv Ment Dis 2017;205(1):4-8. DOI: 10.1097/NMD.0000000000000596.

26. Vayena E, Salathé M, Madoff LC, Brownstein JS. Ethical challenges of big data in public health. PLoS Comput Biol 2015;11(2): e1003904. DOI: 10.1371/journal.pcbi.1003904.

27. Bauer M, Glenn T, Monteith S. Ethical perspectives on recommending digital technology for patients with mental illness. Int J Bipolar Disord 2017;5:6. DOI: 10.1186/s40345-017-0073-9.

28. Chan S, Godwin H, Gonzalez A, Yellowlees PM, Hilty DM. Review of use and integration of mobile apps into psychiatric treatments. Curr Psychiatry Rep 2017;19(12):96. DOI: 10.1007/s11920-017-0848-9.

29. Clar C, Dyakova M, Curtis K, et al. Just telling and selling. Current limitations in the use of digital media in public health: a scoping review. Public Health 
2014;128(12):1066-1075. DOI: 10.1016/j.puhe.2014.09.009.

30. Groß D, Schmidt M. E-Health und Gesundheitsapps aus medizinethischer Sicht. Wollen wir alles, was wir können? Bundesgesundheitsbl 2018;61(3):349-357. DOI: 10.1007/s00103-018-2697-z.

31. Moore S, Tassé A-M, Thorogood A, et al. Consent processes for mobile app mediated research: systematic review. JMIR Mhealth Uhealth 2017;5(8):e126. DOI: 10.2196/mhealth.7014.

32. O' Doherty KC, Christofides E, Yen J, et al. If you build it, they will come. Unintended future uses of organised health data collections. BMCMed Ethics 2016;17(1):54. DOI: 10.1186/s12910-016-0137-x.

33. Sharp M, O'Sullivan D. (2017). Mobile medical apps and mHealth devices. A framework to build medical apps and mHealth Devices in an ethical manner to promote safer use - a literature review. Stud Health Technol Inform 2017;235:363-367. DOI: 10.3233/978-1-61499-753-5-363

34. Huckvale K, Prieto JT, Tilney M, Benghozi P -J, Car $\mathrm{J}$. Unaddressed privacy risks in accredited health and wellness apps. A cross-sectional systematic assessment. BMC Med 2015;13:214. DOI: 10.1186/s12916-015-0444-y.

35. La Vega R de, Miró J. mHealth. A strategic field without a solid scientific soul. A systematic review of pain-related apps. PloS One 2014;9(7):e101312. DOI: 10.1371/journal.pone.0101312.

36. Matthew-Maich N, Harris L, Ploeg J, et al. Designing, implementing, and evaluating mobile health technologies for managing chronic conditions in older adults. A scoping review. JMIR Mhealth Uhealth 2016;4(2): e29. DOI: 10.2196/mhealth.5127.

37. Kunde L, McMeniman E, Parker M. Clinical photography in dermatology. Ethical and medico-legal considerations in the age of digital and smartphone technology. Australas J Dermatol 2013;54(3):192197. DOI: 10.1111/ajd.12063.

38. Nebeker C, Murray K, Holub C, Haughton J, Arredondo EM. Acceptance of mobile health in communities underrepresented in biomedical research. Barriers and ethical considerations for scientists. JMIR Mhealth Uhealth 2017;5(6):e87. DOI: 10.2196/mhealth.6494.

39. Anderson K, Burford O, Emmerton L. Mobile health apps to facilitate self-care. Aqualitative study of user experiences. PloS One 2016;11(5): e0156164. DOI: 10.1371/journal.pone.0156164.

40. Kant I. Grundlegung zur Metaphysik der Sitten. Hamburg, Meiner,1999.

41. Beauchamp TL, Childress JF. Principles of biomedical ethics ( $5^{\text {th }}$ edition). Oxford, Oxford University Press, 2001.
42. Bürgerliches Gesetzbuch. (2013). Gesetz zur Verbesserung der Rechte von Patientinnen und Patienten. Available at: https://www.bgbl.de/xaver/bgbl/start.xav\#__bgbl__\%2 F\%2F*\%5B\%40attr_id\%3D\%27bgbl113s0277.pdf\%2 7\%5D151540106408 accessed 13 December 2018.

43. Charles C, Gafni A, Whelan T. Shared decisionmaking in the medical encounter: What does it mean? (or it takes at least two to tango). Soc Sci Med 1997;44(5):681-692. PMID: 9032835.EU. Regulation (EU) 2016/679 of the European Parliament and of the Council of 27 April 2016. Official Journal of the European Union 2016: L 119/1 - 119/88.

44. Schloemer T, Schröder-Bäck P. Criteria for evaluating transferability of health interventions: a systematic review and thematic synthesis. Implementation Science 2018;13(88):1-17. DOI: 10.1186/s13012-0180751-8. 